Article

\title{
Effects of Fatty Acid Anhydride on the Structure and Thermal Properties of Cellulose-g-Polyoxyethylene (2) Hexadecyl Ether
}

\author{
Wanyong $\mathrm{Yu}^{\dagger}{ }^{\dagger}$, Na Han ${ }^{*}{ }^{\dagger}$, Yongqiang Qian, Xingxiang Zhang ${ }^{*}$ and Wei Li \\ Tianjin Municipal Key Laboratory of Advanced Fiber and Energy Storage, School of Materials Science and \\ Engineering, Tianjin Polytechnic University, Tianjin 300387, China; yu20130513@163.com (W.Y.); \\ qianyongqiang100@sina.com (Y.Q.); hiweilee@gmail.com (W.L.) \\ * Correspondence: hanna@tjpu.edu.cn or hannapolyu@163.com (N.H.); zhangpolyu@aliyun.com (X.Z.); \\ Tel./Fax: +86-22-8395-5054 (X.Z.) \\ + These authors contributed equally to this work.
}

Received: 23 March 2018; Accepted: 20 April 2018; Published: 4 May 2018

\begin{abstract}
Cellulose was premodified by short-chain fatty acid anhydrides, such as acetic anhydride (CA), propionic anhydride (CP), and butyric anhydride (CB), followed by grafting of polyoxyethylene (2) hexadecyl ether $\left(\mathrm{E}_{2} \mathrm{C}_{16}\right)$ using toluene-2,4-diisocyanate as a coupling agent. The feeding molar ratio of $E_{2} C_{16}$ and the anhydroglucose unit (AGU) was fixed at 4:1, and then a series of CA-g- $E_{2} C_{16}$, $\mathrm{CP}-\mathrm{g}-\mathrm{E}_{2} \mathrm{C}_{16}$, and $\mathrm{CB}-\mathrm{g}-\mathrm{E}_{2} \mathrm{C}_{16}$ copolymers were successfully prepared. The structures and properties of the copolymers were characterized using FTIR (fourier transform infrared spectra), ${ }^{1} \mathrm{H}-\mathrm{NMR}$ (Proton nuclear magnetic resonance), DSC (Differential scanning calorimeter), POM (polarized light microscopy), TGA (thermogravimetric analysis) and WAXD (wide-angle X-ray diffraction). It was shown that with the anhydride/AGU ratio increasing, the degree of substitution (DS) value of $\mathrm{E}_{2} \mathrm{C}_{16}$ showed a trend of up first and then down. With the carbon chain length increasing, the DS value of $\mathrm{E}_{2} \mathrm{C}_{16}$ continuously increases. The phase transition temperature and thermal enthalpy of the copolymers increased with an increasing DS value of $\mathrm{E}_{2} \mathrm{C}_{16}$. When the ratio of $\mathrm{CB} / \mathrm{AGU}$ was 1.5:1, the DS of $\mathrm{E}_{2} \mathrm{C}_{16}$ was up to the maximum value of 1.02, and the corresponding melting enthalpy and crystallization enthalpy were $32 \mathrm{~J} / \mathrm{g}$ and $30 \mathrm{~J} / \mathrm{g}$, respectively. The copolymers showed solid-solid phase change behavior. The heat resistant temperature of cellulose-based solid-solid phase change materials was always higher than $270{ }^{\circ} \mathrm{C}$. After the grafting reaction, the crystallinity of $\mathrm{E}_{2} \mathrm{C}_{16}$ decreased, while the crystal type was still hexagonal.
\end{abstract}

Keywords: cellulose; fatty acid anhydride; polyoxyethylene (2) hexadecyl ether; solid-solid phase change

\section{Introduction}

Cellulose is a type of polysaccharide composed of repetitive D-glucose units linked through $\beta(1 \rightarrow 4)$ glycosidic bonds [1]. There are three active $-\mathrm{OH}$ groups in each D-glucose unit, and these can easily form strong intramolecular and intermolecular hydrogen bonds, resulting in smaller distances between molecules and rigid chains. As a result, cellulose is insoluble in common organic solvents and unable to be melt-processed before reaching its decomposition temperature [2,3]. Through modification [4-9], hydrogen bonding was weakened to a certain extent, while a grafted side chain increased molecular distance, which could further improve the solubility of cellulose. Furthermore, the increased molecular distance is helpful for the grafting reaction [10]. When the degree of substitution reaches a critical point, the cellulose derivatives will be melt-processable. 
Vaca-Garcia et al. [11] found that a grafted side chain could weaken the interaction between the molecular chains of cellulose, so that cellulose esters soften and flow at comparatively low temperatures. However, if the side chain is too long $(C>6)$, the long molecular chains account for most of the free volume, resulting in motion of the cellulose ester backbone becoming difficult. That is to say, a flexible long-chain has lost the advantage of lowering the melting point of the cellulose ester. However, if a bulky group (such as benzene) was introduced into the cellulose back-bone, there will be more free volume, and as a result, the thermal flow temperature of cellulose ester will be depressed.

Xiao et al. [12] prepared cellulose esters containing phosphorus, cellulose diphenyl phosphate (C-Dp), and cellulose acetate (CA)-diphenyl phosphate mixed esters (C-A-Dp). C-A-Dp showed clear glass transition behavior. All the products possessed excellent solubility in common organic solvents (e.g., $\mathrm{CHCl}_{3}$, acetone, ethyl acetate), and transparent films of cellulose esters were obtained by solution casting. Furthermore, these cellulose mixed esters exhibited thermoplastic behavior and could be processed by a traditional melt processing method. Luan et al. [13] conducted cellulose esterification in a homogeneous system, where acetic anhydride (CA) and 1-allyl-3-methylimidazolium chloride $(\mathrm{AmimCl})$ were used as the grafting comonomer and solvent, respectively, followed by the ring-opening grafting of L-lactide. As a result, a series of cellulose acetate-g-polylactic acid (CA-g-PLA) copolymers were obtained. The CA-g-PLA copolymers had glass transition temperatures $\left(\mathrm{T}_{\mathrm{g}}\right)$ in the range of $60-130{ }^{\circ} \mathrm{C}$ and exhibited thermoplastic behavior.

In this study, fatty acid anhydride, $\mathrm{CA}$, propionic anhydride (CP), and butyric anhydride (CB) were selected as esterification agents for cellulose, followed by the grafting of polyoxyethylene (2) hexadecyl ether $\left(\mathrm{E}_{2} \mathrm{C}_{16}\right)$ using toluene-2,4-diisocyanate as a coupling agent and the feeding molar ratio of $\mathrm{E}_{2} \mathrm{C}_{16} / \mathrm{AGU}$ fixed at 4:1, and then CA-g- $\mathrm{E}_{2} \mathrm{C}_{16}, \mathrm{CP}-\mathrm{g}-\mathrm{E}_{2} \mathrm{C}_{16}$, and $\mathrm{CB}-\mathrm{g}-\mathrm{E}_{2} \mathrm{C}_{16}$ copolymers were obtained. The effect of carbon chain length and usage amount of fatty acid anhydrides on structures and properties of cellulose-based solid-solid phase change materials were investigated in detail.

\section{Experimental}

\subsection{Materials}

Microcrystalline cellulose (MC, DP (Degree of polymerization) = 220) was purchased from Beijing Fengli Jingqiu Commerce and Trade Co. (Beijing, China); AmimCl was purchased from Shanghai Chengjie Chemical Co. (Shanghai, China); N,N-Dimethylformamide (DMF), dibutyltin dilaurate (DBTDL), acetic anhydride (AA), and pyridine were purchased from Tianjin Guangfu Technology Development Co. (Tianjin, China); propionic anhydride (PA) was purchased from TCI Chemical Reagent Co. (Shanghai, China); butyric anhydride (BA) was purchased from Aladdin Chemical Reagent Co. (Shanghai, China); Toluene 2,4-diisocyanate (TDI) was purchased from Tianjin Fuchen Chemical Reagent Factory. (Tianjin, China); $\mathrm{E}_{2} \mathrm{C}_{16}$ was purchased from Aldrich Chemical Reagent Co. (Shanghai, China); All reagents were used without further purification.

\subsection{Cellulose Esterification}

$\mathrm{MC}$ was dissolved completely in $\mathrm{AmimCl}$ at $80{ }^{\circ} \mathrm{C}$. Then, the desired amounts of fatty acid anhydrides and pyridine were added into cellulose solution. The esterification was conducted for $2 \mathrm{~h}$ at $90{ }^{\circ} \mathrm{C}$.

\subsection{Preparation of Prepolymer}

The desired amounts of TDI and $\mathrm{E}_{2} \mathrm{C}_{16}$ (molar ratio 1.1:1) were dissolved in DMF separately. $\mathrm{E}_{2} \mathrm{C}_{16}$ solution was added dropwise into the TDI solution with continuous stirring at $25{ }^{\circ} \mathrm{C}$ for $15 \mathrm{~min}$, and then the reaction continued for $60 \mathrm{~min}$. The prepolymer solution was obtained when the reaction finished. 


\subsection{Preparation of Cellulose-Based Copolymers}

The prepolymer solution and DBTDL ( $0.1 \mathrm{wt} \%$ of TDI) were added to cellulose ester solution. The mixture was stirred at $90^{\circ} \mathrm{C}$ for $6 \mathrm{~h}$. When the grafting reaction was complete, the reaction mixture was precipitated in distilled water for $12 \mathrm{~h}$. Then, the crude product was filtered and soaked in acetone for another $48 \mathrm{~h}$ to dissolve ungrafted prepolymer in precipitation. After that, the product was filtered, dried, and weighed.

The synthesis procedure of $\mathrm{CA}-\mathrm{g}-\mathrm{E}_{2} \mathrm{C}_{16}, \mathrm{CP}-\mathrm{g}-\mathrm{E}_{2} \mathrm{C}_{16}$, and $\mathrm{CB}-\mathrm{g}-\mathrm{E}_{2} \mathrm{C}_{16}$ copolymers are shown in Scheme 1 , sample numbers and raw material feeding ratios are listed in Table 1.

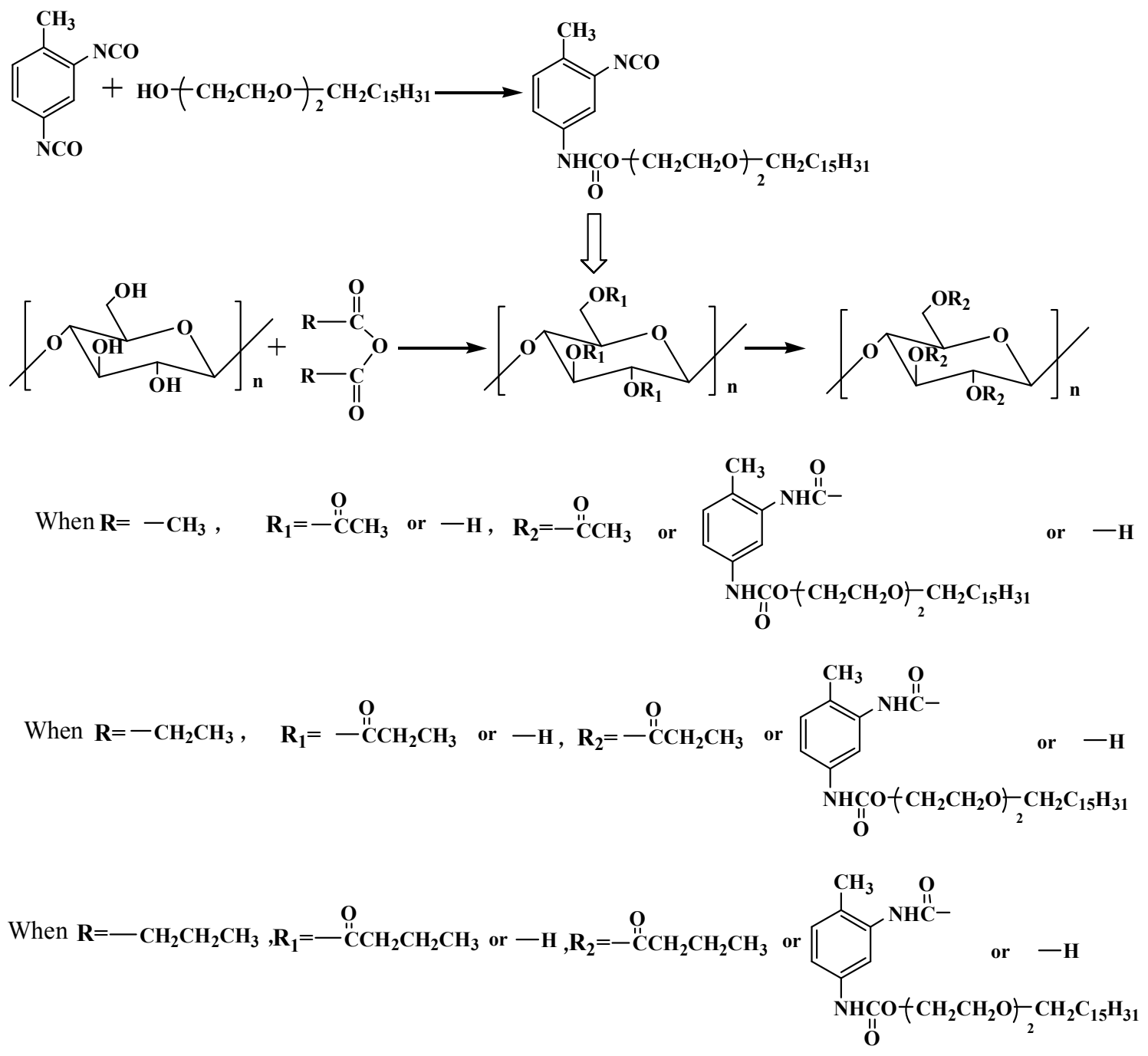

Scheme 1. Synthesis mechanism of $\mathrm{CA}-\mathrm{g}-\mathrm{E}_{2} \mathrm{C}_{16}, \mathrm{CP}-\mathrm{g}-\mathrm{E}_{2} \mathrm{C}_{16}$, and $\mathrm{CB}-\mathrm{g}-\mathrm{E}_{2} \mathrm{C}_{16}$ copolymers. 
Table 1. Sample number and raw material feeding ratios.

\begin{tabular}{cccccc}
\hline Sample No. & $\begin{array}{c}\text { CA:AGU } \\
\text { (mol:mol) }\end{array}$ & $\begin{array}{c}\text { CP:AGU } \\
\text { (mol:mol) }\end{array}$ & $\begin{array}{c}\text { CB:AGU } \\
\text { (mol:mol) }\end{array}$ & $\begin{array}{c}\text { Pyridine:AGU } \\
\text { (mol:mol) }\end{array}$ & $\begin{array}{c}\text { E }_{2} \mathbf{C}_{\mathbf{1 6}} \text { :AGU } \\
\text { (mol:mol) }\end{array}$ \\
\hline S-B & - & - & - & $2.5: 1$ & $4: 1$ \\
A1 & $0.5: 1$ & - & - & $2.5: 1$ & $4: 1$ \\
A2 & $1.0: 1$ & - & - & $2.5: 1$ & $4: 1$ \\
A3 & $1.5: 1$ & - & - & $2.5: 1$ & $4: 1$ \\
A4 & $2.0: 1$ & - & - & $2.5: 1$ & $4: 1$ \\
P1 & - & $0.5: 1$ & - & $2.5: 1$ & $4: 1$ \\
P2 & - & $1.0: 1$ & - & $2.5: 1$ & $4: 1$ \\
P3 & - & $1.5: 1$ & - & $2.5: 1$ & $4: 1$ \\
P4 & - & $2.0: 1$ & - & $2.5: 1$ & $4: 1$ \\
B1 & - & - & $0.5: 1$ & $2.5: 1$ & $4: 1$ \\
B2 & - & - & $1.0: 1$ & $2.5: 1$ & $4: 1$ \\
B3 & - & - & $1.5: 1$ & $2.5: 1$ & $2.5: 1$ \\
B4 & - & - & $2.0: 1$ & & 4 \\
\hline
\end{tabular}

S-B; A, P, and B are just sample numbers. S-B: Cellulose-g-E2C16 copolymer (no acid anhydride added); A: CA-g-E2C16 copolymer; P: CP-g-E2C16 copolymer; B: CB-g-E2C16 copolymer.

\subsection{Characterization}

\subsubsection{FTIR}

Fourier transform infrared spectra (FTIR) were collected using a Bruker Tensor-37 Fourier (Germany) transform infrared spectrometer. The dried samples were tested by the $\mathrm{KBr}$ disc technique, and infrared spectra were recorded in the range of $4000-400 \mathrm{~cm}^{-1}$.

\subsection{2. ${ }^{1} \mathrm{H}-\mathrm{NMR}$}

Proton nuclear magnetic resonance $\left({ }^{1} \mathrm{H}-\mathrm{NMR}\right)$ spectroscopy was performed using an Avance AV-300 MHz nuclear magnetic resonance spectrometer. The solvent was dimethyl sulfoxide- $d_{6}$.

The degree of substitution (DS) of fatty acid group and $\mathrm{E}_{2} \mathrm{C}_{16}$ could be calculated by ${ }^{1} \mathrm{H}-\mathrm{NMR}$ results.

$D S_{1}$ of an acetyl group could be calculated by Equation (1) as follows:

$$
D S_{1}=\frac{7}{3} \cdot \frac{I_{\mathrm{CH} 3}}{I_{A G U}}
$$

where $I_{A G U}$ is the integral intensity of the hydrogen atoms in the AGU and $\mathrm{C}_{6}(7 \mathrm{H}, \sigma=3.0 \sim 5.5)$ and $I_{\mathrm{CH} 3}$ is the integral intensity of the $-\mathrm{CH}_{3}$ group $(3 \mathrm{H}, \delta=1.7 \sim 2.2)$ in an acetyl group.

$D S_{1}$ of a propionyl group could be also calculated by Equation (1), where $I_{\mathrm{CH} 3}$ is the integral intensity of the $-\mathrm{CH}_{3}$ group $(3 \mathrm{H}, \delta=1.1)$ in a propionyl group.

$D S_{1}$ of a butyryl group could be calculated by Equation (2) as follows:

$$
D S_{1}=\frac{7}{2} \cdot \frac{I_{C H 2}}{I_{A G U}}
$$

where $I_{C H 2}$ is the integral intensity of the $-\mathrm{CH}_{2}-$ group $(2 \mathrm{H}, \delta=1.6)$ in a butyryl group.

$D S_{2}$ of $\mathrm{E}_{2} \mathrm{C}_{16}$ could be calculated by Equation (3) as follows:

$$
D S_{2}=\frac{7}{3} \cdot \frac{I_{\text {phenyl }}}{I_{A G U}}
$$

where $I_{\text {phenyl }}$ is the integral intensity of benzene ( $\left.3 \mathrm{H}, \delta=7.0 \sim 7.4\right)$ in TDI. 


\subsubsection{DSC}

Differential scanning calorimetry (DSC) was performed using a NETZSCH DSC 200 F3 (Germany). The samples were heated from $20^{\circ} \mathrm{C}$ to $250{ }^{\circ} \mathrm{C}$ at $30^{\circ} \mathrm{C} / \mathrm{min}$ to eliminate the thermal history. Then, the samples were cooled to $-20^{\circ} \mathrm{C}$ and heated from $-20^{\circ} \mathrm{C}$ to $250{ }^{\circ} \mathrm{C}$ at $10{ }^{\circ} \mathrm{C} / \mathrm{min}$. All heating and cooling processes were performed under a nitrogen atmosphere. The thermal data were read from the second heating run and the first cooling run.

\subsubsection{POM}

The type of phase change was carried out with hot-stage polarized light microscopy using a BX51TRF. Samples were firstly heated to $100{ }^{\circ} \mathrm{C}$ and then cooled down to room temperature $\left(20^{\circ} \mathrm{C}\right)$ in order to remove the thermal history. Subsequently, they were heated to $100{ }^{\circ} \mathrm{C}$ at a heating rate of $10^{\circ} \mathrm{C} / \mathrm{min}$ to observe the thermal behaviors.

\subsubsection{TG}

Thermogravimetric analysis (TGA) was carried out in a NETZSCH STA $449 \mathrm{~F} 3$ from $40{ }^{\circ} \mathrm{C}$ to $800{ }^{\circ} \mathrm{C}$ at a heating rate of $10^{\circ} \mathrm{C} / \mathrm{min}$ under a nitrogen atmosphere.

\subsubsection{WAXD}

Wide-angle X-ray diffraction (WAXD) was recorded on a D/MAX-2500 under conditions of $150 \mathrm{~mA}$ and $40 \mathrm{kV}$ at $0{ }^{\circ} \mathrm{C}$. The $\mathrm{X}$-ray source is an $18-\mathrm{kW}$ rotating anode $\mathrm{X}$-ray generator equipped with a $\mathrm{Cu}$ target. The incident $\mathrm{X}$-ray beam was monochromated by a pyrolytic graphite, and the data were measured in a range of $2 \theta=4^{\circ} \sim 40^{\circ}, \lambda=1.54 \AA$.

\section{Results and Discussion}

\subsection{FTIR}

Figure 1 displays the FTIR spectra of cellulose, $\mathrm{E}_{2} \mathrm{C}_{16}, \mathrm{CA}-\mathrm{g}-\mathrm{E}_{2} \mathrm{C}_{16}(\mathrm{~A} 3), \mathrm{CP}-\mathrm{g}-\mathrm{E}_{2} \mathrm{C}_{16}$ (P3), and CB-g- $E_{2} C_{16}$ (B3) copolymers. In the spectrum of cellulose, the wide peak at approximately $3200 \mathrm{~cm}^{-1}$ is assigned to the absorption band of the hydroxyl groups on the AGU, whose intensity was significantly reduced in the spectra of copolymers. In the spectrum of $E_{2} C_{16}$, the peaks at $2852 \mathrm{~cm}^{-1}$ and $2920 \mathrm{~cm}^{-1}$ are assigned to the characteristic absorption bands of the ethylene glycol repeat units and the saturated alkane group of $\mathrm{E}_{2} \mathrm{C}_{16}$, respectively, which also appeared in the spectra of $\mathrm{CA}-\mathrm{g}-\mathrm{E}_{2} \mathrm{C}_{16}$ (A3), $\mathrm{CP}-\mathrm{g}-\mathrm{E}_{2} \mathrm{C}_{16}$ (P3), and CB-g- $\mathrm{E}_{2} \mathrm{C}_{16}$ (B3) copolymers. In the spectrum of copolymers, $1385 \mathrm{~cm}^{-1}$ is assigned to the absorption band of $\mathrm{C}-\mathrm{H}, 1230 \mathrm{~cm}^{-1}$ is assigned to the absorption band of $\mathrm{C}-\mathrm{O}$, and $1750 \mathrm{~cm}^{-1}$ is assigned to the absorption band of $\mathrm{C}=\mathrm{O}$. It is demonstrated that fatty acid groups (acetyl group, propionyl group, and butyryl group) were successfully linked onto the cellulose backbone. We can observe the characteristic absorption band of the conjugated $\mathrm{C}=\mathrm{C}$ double bond of the benzene ring in TDI at $1603 \mathrm{~cm}^{-1}$ and the amide bands [14] at $1700 \mathrm{~cm}^{-1}$ and $1545 \mathrm{~cm}^{-1}$ in the spectra of copolymers, which indicated that the $\mathrm{E}_{2} \mathrm{C}_{16}$ was successfully grafted onto the cellulose backbone through TDI. Based on the analysis above, it could be declared that CA-g- $\mathrm{E}_{2} \mathrm{C}_{16}, \mathrm{CP}-\mathrm{g}-\mathrm{E}_{2} \mathrm{C}_{16}$, and CB-g- $\mathrm{E}_{2} \mathrm{C}_{16}$ copolymers were successfully synthesized. 


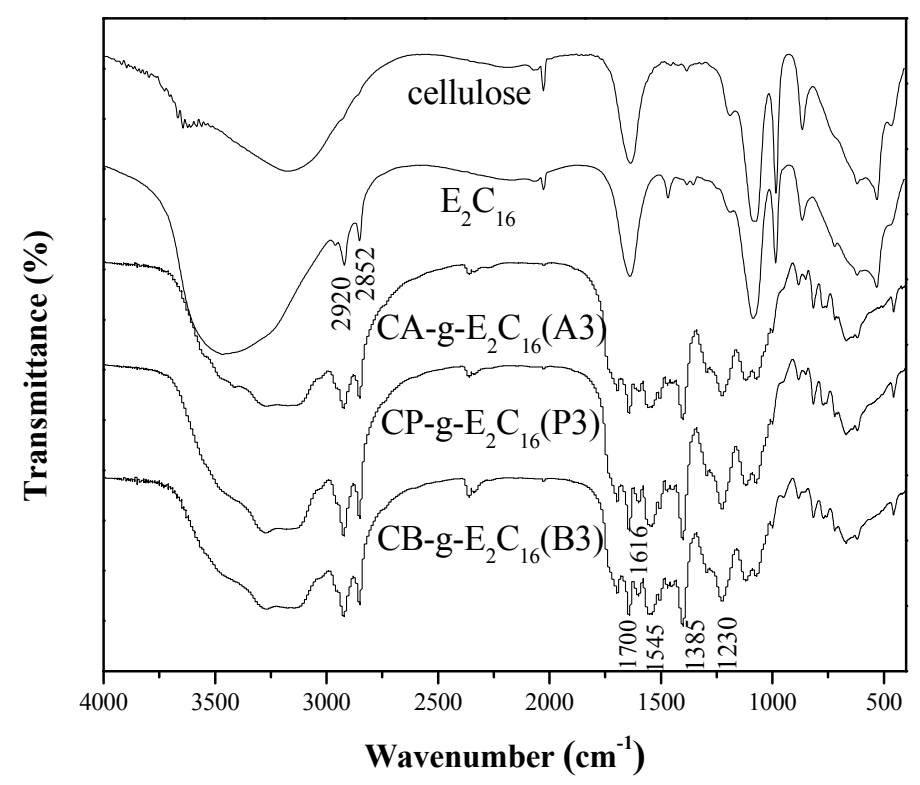

Figure 1. FTIR spectra of cellulose, $\mathrm{E}_{2} \mathrm{C}_{16}, \mathrm{CA}-\mathrm{g}-\mathrm{E}_{2} \mathrm{C}_{16}$ (A3), CP-g- $\mathrm{E}_{2} \mathrm{C}_{16}$ (P3), and CB-g- $\mathrm{E}_{2} \mathrm{C}_{16}$ (B3) copolymers.

\section{2. ${ }^{1} H-N M R$}

Figure 2 shows the ${ }^{1} \mathrm{H}-\mathrm{NMR}$ spectrum of $\mathrm{CA}-\mathrm{g}-\mathrm{E}_{2} \mathrm{C}_{16}$ (sample $\mathrm{A} 3, \mathrm{a}$ ), $\mathrm{CP}$-g- $\mathrm{E}_{2} \mathrm{C}_{16}$ (sample $\mathrm{P} 3, \mathrm{~b}$ ), and $\mathrm{CB}-\mathrm{g}-\mathrm{E}_{2} \mathrm{C}_{16}$ (sample B3, c) copolymers. The peaks at $\delta=1.7 \sim 2.2$ were assigned to the signals of the methyl protons of acetyl group, the peak at $\delta=1.1$ was assigned to the signal of the methyl protons of propionyl group, the peak at $\delta=2.4$ was assigned to the signal of the methylene protons of propionyl group, the peak at $\delta=0.9$ was assigned to the signal of the methyl protons of butyryl group, the peaks at $\delta=1.6$ and $\delta=2.3$ were assigned to the signals of the methylene protons of butyryl group [15], and the peaks at $\sigma=3.0 \sim 5.5$ were assigned to the signals of the protons in the glucose unit ring and C6. It is also demonstrated that fatty acid groups were successfully linked onto the cellulose backbone. The peak at $\sigma=0.85$ was assigned to the signal of the methyl protons of the alkyl chain in $\mathrm{E}_{2} \mathrm{C}_{16}$, the peaks at $\sigma=1.1 \sim 1.7$ were assigned to the signals of the methylene protons of the alkyl chain in $\mathrm{E}_{2} \mathrm{C}_{16}$, the peak at $\sigma=3.4$ was assigned to the signal of the methylene protons adjacent to the ether bond of the alkyl chain in $\mathrm{E}_{2} \mathrm{C}_{16}$, the peaks at $\sigma=3.5 \sim 3.8$ were assigned to the signals of the protons of the ethylene glycol repeat units of $\mathrm{E}_{2} \mathrm{C}_{16}$, and the peaks at $\sigma=7.0 \sim 7.4$ were assigned to the signals of the protons in the benzene ring of TDI. Based on the analysis above, it is evident that CA-g- $\mathrm{E}_{2} \mathrm{C}_{16}, \mathrm{CP}-\mathrm{g}-\mathrm{E}_{2} \mathrm{C}_{16}$, and CB-g- $\mathrm{E}_{2} \mathrm{C}_{16}$ copolymers were successfully synthesized.

The DS values of CA-g- $E_{2} \mathrm{C}_{16}, \mathrm{CP}-\mathrm{g}-\mathrm{E}_{2} \mathrm{C}_{16}$, and CB-g- $\mathrm{E}_{2} \mathrm{C}_{16}$ copolymers are shown in Table 2. When the ratio of acid anhydride/AGU increased from 0.5:1 to 1.5:1, both $D S_{1}$ and $D S_{2}$ increased significantly. When the ratio of acid anhydride/AGU increased to $2: 1, D S_{1}$ continued to increase while $D S_{2}$ dropped. When the ratio of acid anhydride/AGU increased within a certain range, $D S_{1}$ and the distance between cellulose molecules increased due to the anhydride side group. This is helpful for the grafting reaction of $E_{2} C_{16}$, so $D S_{2}$ increased, as expected. However, when the feeding ratio of anhydride/AGU was higher than $1.5 \mathrm{~mol} \%, D S_{1}$ continued to increase, the number of free hydroxyl groups in AGU decreased, and the intermolecular steric hindrance became stronger, leading to a lower $D S_{2}$ value. 


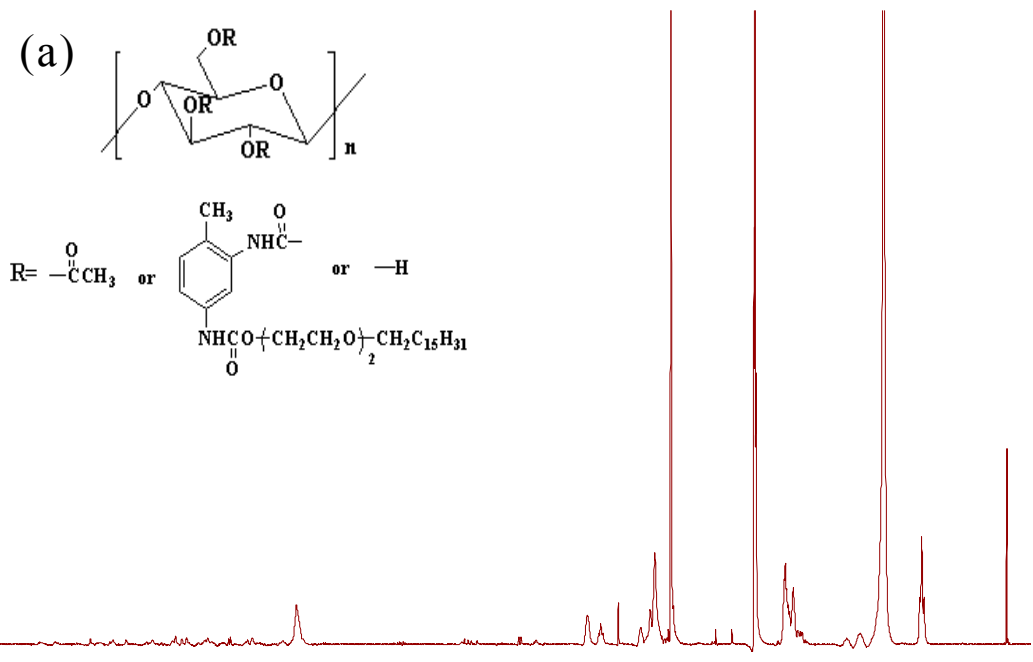

(b)

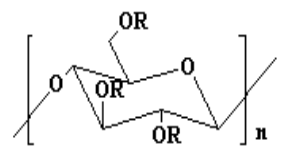

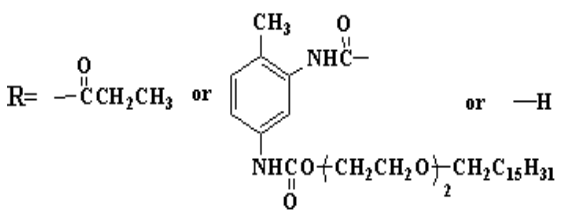

(c)

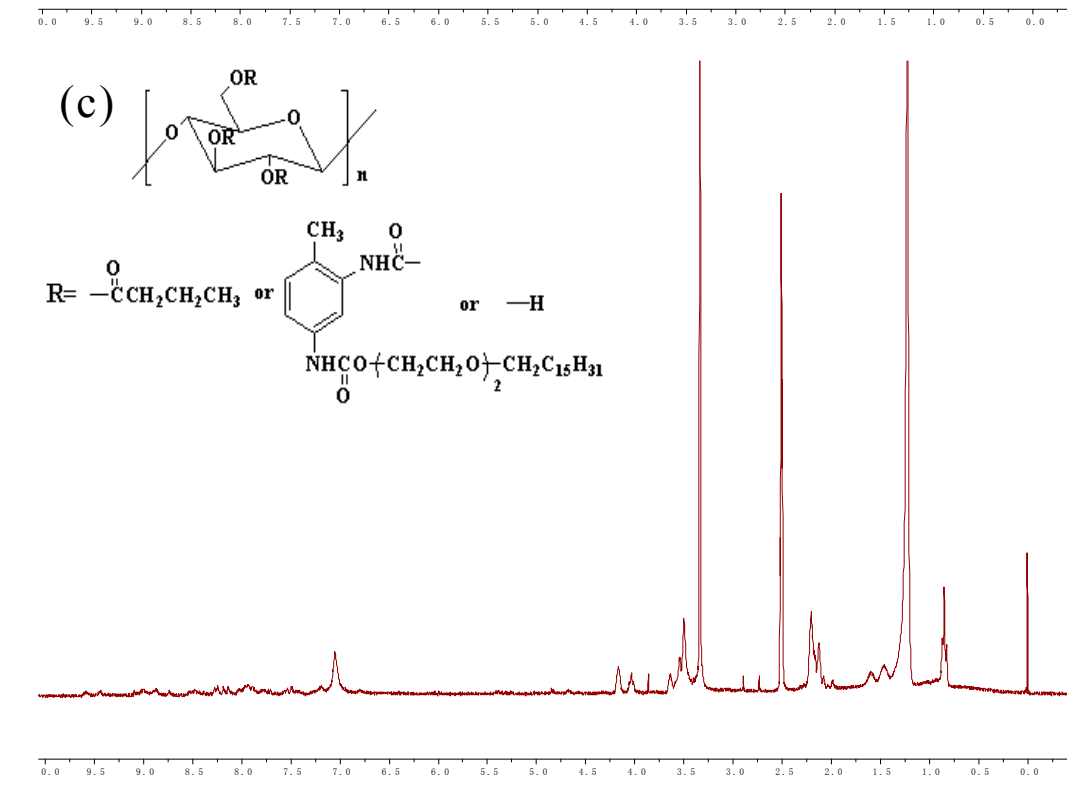

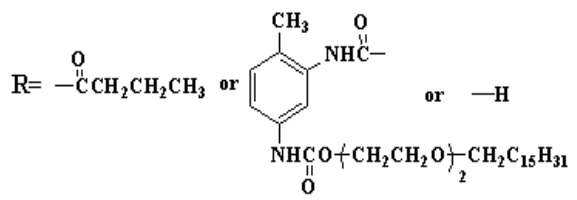
MuN
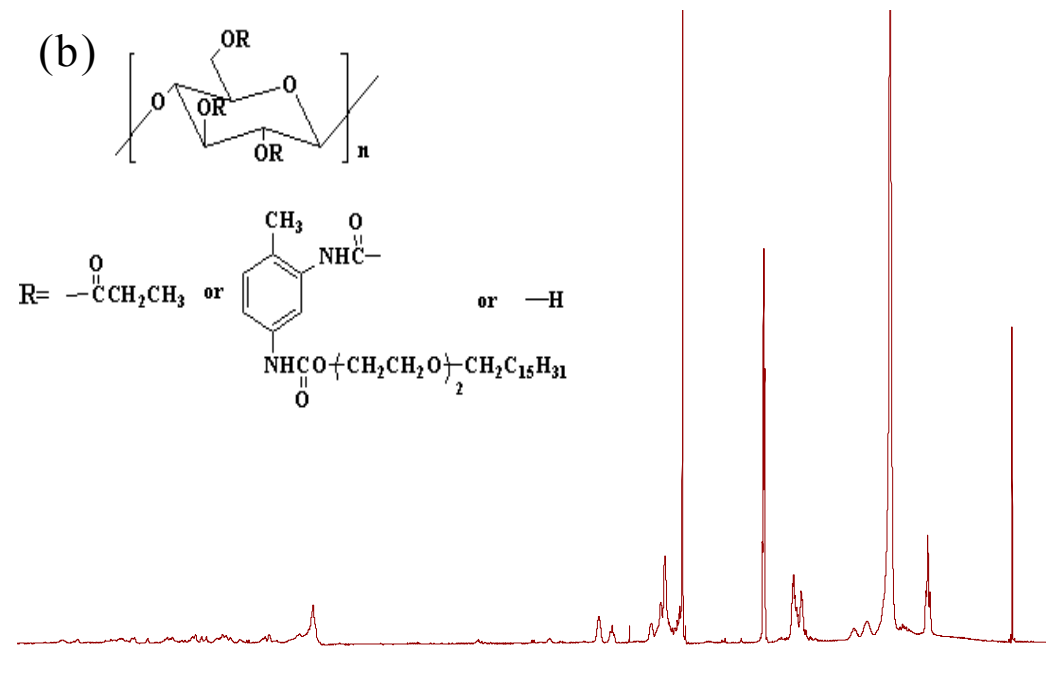

Figure 2. ${ }^{1} \mathrm{H}-\mathrm{NMR}$ spectra of (a) CA-g- $\mathrm{E}_{2} \mathrm{C}_{16}$ (A3), (b) CP-g- $\mathrm{E}_{2} \mathrm{C}_{16}$ (P3), and (c) CB-g- $\mathrm{E}_{2} \mathrm{C}_{16}$ (B3) copolymers. 
Table 2. Degree of substitution (DS) values of different samples.

\begin{tabular}{ccccccc}
\hline Sample No. & $\begin{array}{c}\text { AA:AGU } \\
\text { (mol:mol) }\end{array}$ & $\begin{array}{c}\text { PA:AGU } \\
\text { (mol:mol) }\end{array}$ & $\begin{array}{c}\text { BA:AGU } \\
\text { (mol:mol) }\end{array}$ & $\begin{array}{c}\mathbf{E}_{\mathbf{2}} \mathbf{C}_{\mathbf{1 6}} \text { :AGU } \\
\text { (mol:mol) }\end{array}$ & DS $_{\mathbf{1}} \mathbf{a}$ & DS $_{\mathbf{2}} \mathbf{b}^{-\mathbf{m}}$ \\
\hline S-B & - & - & - & $4: 1$ & - & 1.01 \\
A1 & $0.5: 1$ & - & - & $4: 1$ & 0.35 & 0.59 \\
A2 & $1.0: 1$ & - & - & $4: 1$ & 0.58 & 0.75 \\
A3 & $1.5: 1$ & - & - & $4: 1$ & 0.75 & 0.86 \\
A4 & $2.0: 1$ & - & - & $4: 1$ & 1.09 & 0.52 \\
P1 & - & $0.5: 1$ & - & $4: 1$ & 0.36 & 0.62 \\
P2 & - & $1.0: 1$ & - & $4: 1$ & 0.55 & 0.80 \\
P3 & - & $1.5: 1$ & - & $4: 1$ & 0.79 & 0.97 \\
P4 & - & $2.0: 1$ & - & $4: 1$ & 1.00 & 0.88 \\
B1 & - & - & $0.5: 1$ & $4: 1$ & 0.35 & 0.79 \\
B2 & - & - & $1.0: 1$ & $4: 1$ & 0.54 & 0.93 \\
B3 & - & - & $1.5: 1$ & $4: 1$ & 0.75 & 1.02 \\
B4 & - & - & $2.0: 1$ & $4: 1$ & 1.04 & 0.91 \\
\hline
\end{tabular}

${ }^{a}$ : DS value of short-chain fatty acyl group; ${ }^{b}:$ DS value of $E_{2} C_{16}$.

The calculated results showed that $D S_{2}$ becomes larger with increasing carbon atom number of acid anhydride because the distance between cellulose molecules increases and the free volume region increases. However, the $D S_{1}$ value of cellulose-based copolymers were roughly equal. This is because with the carbon atom number increasing, the effect of increasing distance between cellulose molecules becomes stronger, which is helpful for the grafting reaction of $\mathrm{E}_{2} \mathrm{C}_{16}$. We can conclude that the effect of increasing cellulose molecule spacing is in the order of $\mathrm{BC}>\mathrm{PC}>\mathrm{AC}$. When the ratio of $\mathrm{BC} / \mathrm{AGU}$ was 1.5:1, $D S_{2}$ of $E_{2} C_{16}$ in all three types of copolymers reached the maximum value of 1.02.

\subsection{DSC}

Figures 3 and 4 and Table 3 show the thermal transition behavior of $\mathrm{E}_{2} \mathrm{C}_{16}, \mathrm{CA}-\mathrm{g}-\mathrm{E}_{2} \mathrm{C}_{16}$, $\mathrm{CP}-\mathrm{g}-\mathrm{E}_{2} \mathrm{C}_{16}$, and $\mathrm{CB}-\mathrm{g}-\mathrm{E}_{2} \mathrm{C}_{16}$ copolymers with different $\mathrm{DS}$ values. Pure $\mathrm{E}_{2} \mathrm{C}_{16}$ possessed distinct phase transition peaks with large latent heats $\left(\Delta \mathrm{H}_{\mathrm{m}}=104 \mathrm{~J} / \mathrm{g} ; \Delta \mathrm{H}_{\mathrm{c}}=95 \mathrm{~J} / \mathrm{g}\right)$, proving it is a type of phase-change material with good thermal storage capacity. For CA-g- $\mathrm{E}_{2} \mathrm{C}_{16}, \mathrm{CP}-\mathrm{g}-\mathrm{E}_{2} \mathrm{C}_{16}$, and CB-g- $\mathrm{E}_{2} \mathrm{C}_{16}$ copolymers, $\mathrm{E}_{2} \mathrm{C}_{16}$ is the working phase change material (PCM), while the cellulosic backbone acts as the supporting skeleton for fixing the $\mathrm{E}_{2} \mathrm{C}_{16}$ chains and contributes nothing to the enthalpy. Therefore, the thermal behavior of cellulose-based copolymers is in line with the changing trend of DS, as mentioned above.

The enthalpy is a linear relationship with the crystalline d-spacing $[10,16]$. As shown in Table 3 , when the feeding ratio of fatty acid anhydride/AGU increased from 0.5:1 to 2.0:1, the value of $D S_{1}$ continuously increased, while the $D S_{2}$ reached a maximum value at 1.5:1 of fatty acid anhydride/AGU. It is ascribed to the steric hindrance effect derived from fatty acid anhydride. The reactivity of free radical polymerization is strongly affected by the steric hindrance of side chains, which rises with increase of the DS of side chains. Therefore, with an increasing fatty acid anhydride/AGU ratio, phase change enthalpy $(\Delta \mathrm{H}), \mathrm{T}_{\mathrm{mo}}$ and $\mathrm{T}_{\mathrm{do}}$ of the copolymers all exhibited a similar trend of first increasing and then decreasing, and they also reached a maximum value at 1.5:1 of fatty acid anhydride/AGU. Similarly, when the acid anhydride content was the same, the phase change enthalpy of the copolymers also increased with increasing the number of fatty acid anhydride carbon atoms, which is in line with the changing trend of $D S_{2}$. For the $\mathrm{CB}-\mathrm{g}-\mathrm{E}_{2} \mathrm{C}_{16}$ copolymer, when the feeding ratio of $\mathrm{BC} / \mathrm{AGU}$ was $1.5: 1, D S_{2}$ in all copolymers reached the maximum value of 1.02 , while $\Delta \mathrm{H}_{\mathrm{m}}$ and $\Delta \mathrm{H}_{\mathrm{c}}$ also showed the maximum values of $32 \mathrm{~J} / \mathrm{g}$ and $30 \mathrm{~J} / \mathrm{g}$, respectively. In addition, compared with pure $\mathrm{E}_{2} \mathrm{C}_{16}$, the phase transition peaks of the copolymers shifted slightly to a lower temperature due to the increase in the side-chain crystal imperfection. 

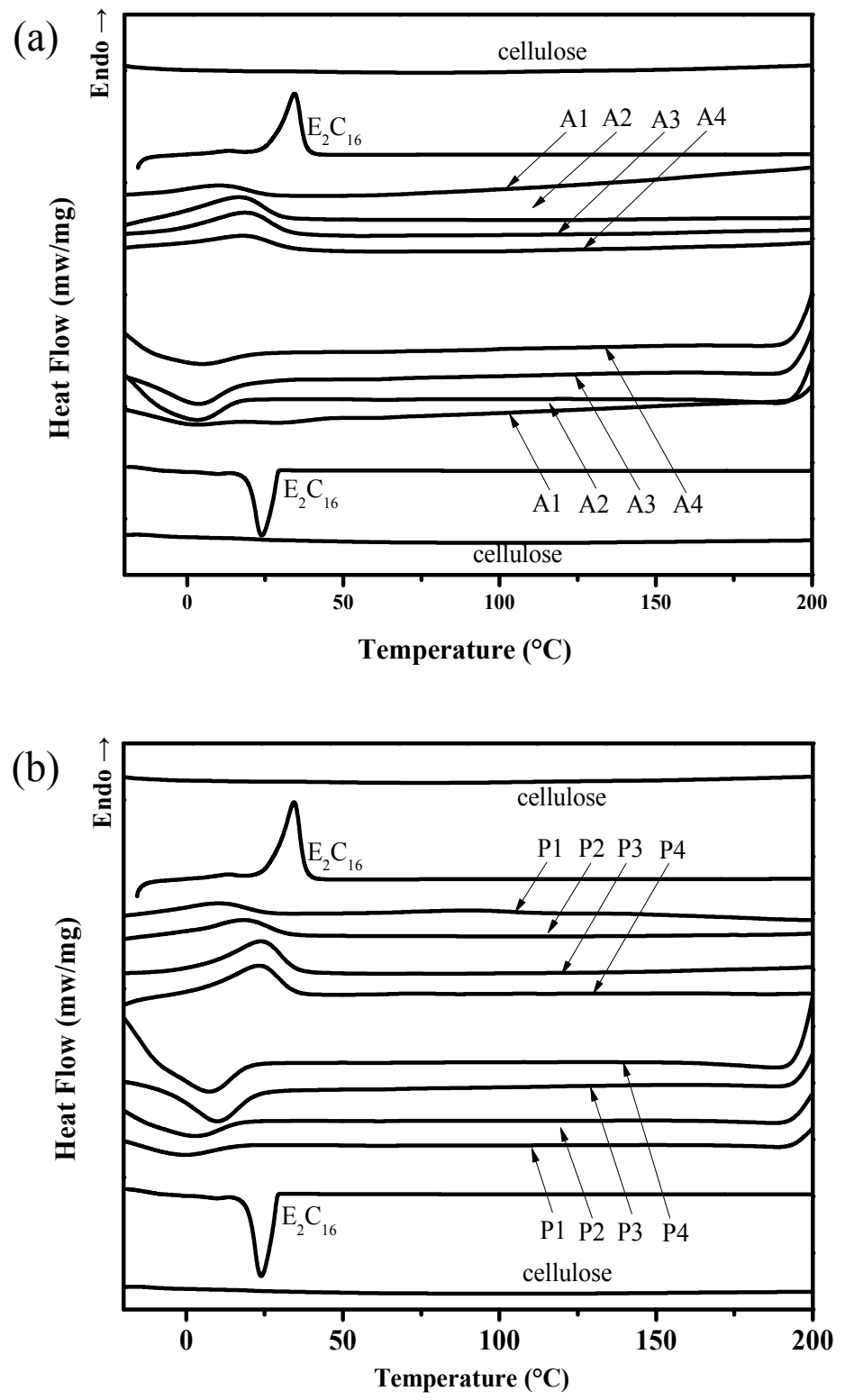

(c)

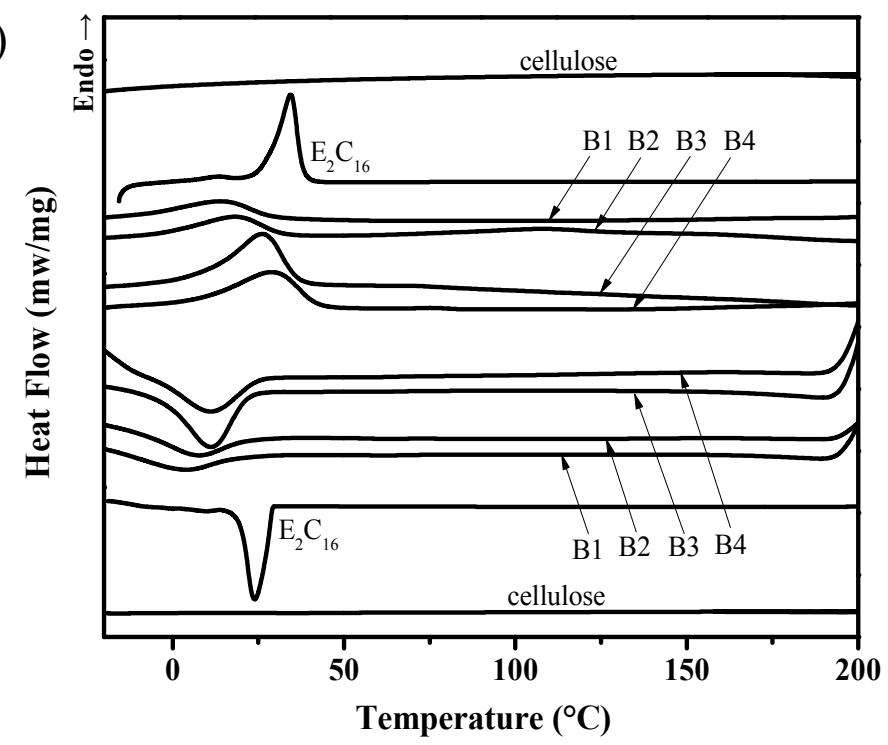

Figure 3. DSC curves of cellulose, $\mathrm{E}_{2} \mathrm{C}_{16}$, (a) CA-g- $\mathrm{E}_{2} \mathrm{C}_{16} ;$ (b) $\mathrm{CP}-\mathrm{g}-\mathrm{E}_{2} \mathrm{C}_{16}$, and (c) CB-g- $\mathrm{E}_{2} \mathrm{C}_{16}$ copolymers. 


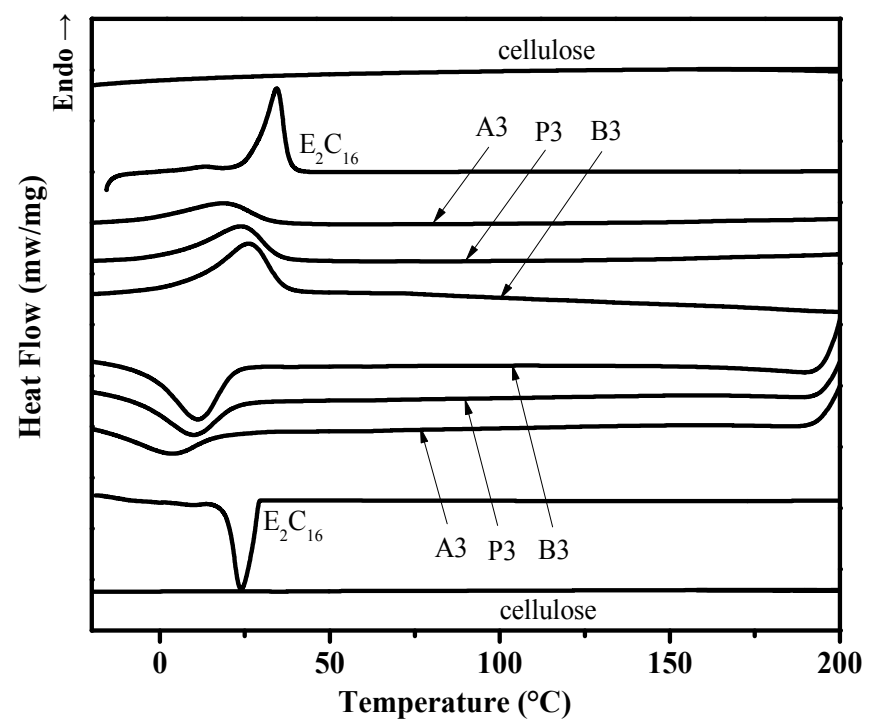

Figure 4. DSC curves of cellulose, $\mathrm{E}_{2} \mathrm{C}_{16}$, cellulose-g- $\mathrm{E}_{2} \mathrm{C}_{16}(\mathrm{~S}-\mathrm{B}), \mathrm{CA}-\mathrm{g}-\mathrm{E}_{2} \mathrm{C}_{16}(\mathrm{~A} 3), \mathrm{CP}-\mathrm{g}-\mathrm{E}_{2} \mathrm{C}_{16}(\mathrm{P} 3)$, and $\mathrm{CB}-\mathrm{g}-\mathrm{E}_{2} \mathrm{C}_{16}$ (B3) copolymers.

Table 3. Thermal transitions of $\mathrm{E}_{2} \mathrm{C}_{16}$, cellulose-g- $\mathrm{E}_{2} \mathrm{C}_{16}(\mathrm{~S}-\mathrm{B}), \mathrm{CA}-\mathrm{g}-\mathrm{E}_{2} \mathrm{C}_{16}, \mathrm{CP}-\mathrm{g}-\mathrm{E}_{2} \mathrm{C}_{16}$, and CB-g- $\mathrm{E}_{2} \mathrm{C}_{16}$ copolymers.

\begin{tabular}{|c|c|c|c|c|c|c|c|c|c|c|}
\hline \multirow{2}{*}{$\begin{array}{c}\text { Sample } \\
\text { No. }\end{array}$} & \multirow[b]{2}{*}{$D S_{1}$} & \multirow[b]{2}{*}{$D S_{2}$} & \multirow{2}{*}{$\begin{array}{c}W_{E 2 C 16}{ }^{a} \\
\text { (wt \%) }\end{array}$} & \multicolumn{3}{|c|}{ Heating } & \multirow[b]{2}{*}{$\underset{(\mathrm{J} / \mathrm{g})}{\Delta \mathrm{H}_{\mathrm{m}}}$} & \multicolumn{3}{|c|}{ Cooling } \\
\hline & & & & $\begin{array}{l}\mathrm{T}_{\mathrm{mo}}{ }^{\mathrm{b}} \\
\left({ }^{\circ} \mathrm{C}\right)\end{array}$ & $\begin{array}{l}\mathrm{T}_{\mathrm{mp}}{ }^{\mathrm{c}} \\
\left({ }^{\circ} \mathrm{C}\right)\end{array}$ & $\begin{array}{c}\Delta \mathbf{H}_{\mathrm{m}} \\
(\mathrm{J} / \mathrm{g})\end{array}$ & & $\begin{array}{l}\mathrm{T}_{\mathrm{co}} \mathrm{e} \\
\left({ }^{\circ} \mathrm{C}\right)\end{array}$ & $\begin{array}{l}T_{\mathrm{cp}}{ }^{\mathrm{f}} \\
\left({ }^{\circ} \mathrm{C}\right)\end{array}$ & $\begin{array}{l}\Delta \mathrm{H}_{\mathrm{c}} \\
(\mathrm{J} / \mathrm{g})\end{array}$ \\
\hline $\mathrm{E}_{2} \mathrm{C}_{16}$ & - & - & 100 & 27.6 & 34.4 & 104 & 104 & 29.2 & 23.9 & 95 \\
\hline $\mathrm{A} 1$ & 0.35 & 0.59 & 41 & 5.4 & 10.4 & 13 & 43 & 15.3 & -0.6 & 13 \\
\hline A2 & 0.58 & 0.75 & 44 & 6.3 & 16.5 & 16 & 46 & 16.8 & 2.8 & 15 \\
\hline $\mathrm{A} 3$ & 0.75 & 0.86 & 45 & 8.0 & 18.6 & 17 & 47 & 17.6 & 3.5 & 20 \\
\hline A4 & 1.09 & 0.52 & 36 & 4.5 & 9.8 & 11 & 38 & 15.0 & -1.0 & 12 \\
\hline P1 & 0.36 & 0.62 & 41 & 2.8 & 11.7 & 12 & 43 & 12.8 & 0.7 & 13 \\
\hline P2 & 0.55 & 0.80 & 44 & 9.7 & 18.3 & 18 & 46 & 14.1 & 2.7 & 17 \\
\hline P3 & 0.79 & 0.97 & 46 & 13.7 & 23.9 & 27 & 48 & 20.8 & 9.8 & 28 \\
\hline P4 & 1.00 & 0.88 & 44 & 13.2 & 23.2 & 21 & 46 & 19.4 & 7.2 & 21 \\
\hline B1 & 0.35 & 0.79 & 45 & 5.8 & 14.0 & 16 & 46 & 18.9 & 3.3 & 17 \\
\hline B2 & 0.54 & 0.93 & 46 & 11.0 & 21.7 & 24 & 48 & 21.4 & 9.3 & 24 \\
\hline B3 & 0.75 & 1.02 & 46 & 14.2 & 26.1 & 32 & 48 & 23.3 & 11.1 & 30 \\
\hline B4 & 1.04 & 0.91 & 43 & 13.7 & 25.0 & 24 & 45 & 21.0 & 9.5 & 23 \\
\hline
\end{tabular}

${ }^{a}$ : the mass percent of $\mathrm{E}_{2} \mathrm{C}_{16}$ in copolymer; ${ }^{\mathrm{b}}$ : the onset temperature of the melting peak; ${ }^{\mathrm{c}}$ : the peak temperature of the melting peak; ${ }^{\mathrm{d}}$ : the $\Delta \mathrm{H}_{\mathrm{m}}$ of PCMs if in the condition of blending; ${ }^{\mathrm{e}}$ : the onset temperature of the crystallization peak; ${ }^{\mathrm{f}}$ : the peak temperature of the crystallization peak.

As shown in Figure 4, with increasing number of fatty acid anhydride carbon atoms, $\mathrm{T}_{\mathrm{m}}$ and $\mathrm{T}_{\mathrm{c}}$ of the copolymers follow the order CA-g- $\mathrm{E}_{2} \mathrm{C}_{16}<\mathrm{CP}-\mathrm{g}-\mathrm{E}_{2} \mathrm{C}_{16}<\mathrm{CB}-\mathrm{g}-\mathrm{E}_{2} \mathrm{C}_{16}$. Furthermore, the peak area follows the same order. This means that increasing the length of the carbon chain helps in improving the thermal storage capability.

Compared with $\Delta \mathrm{H}_{\mathrm{m}}{ }^{*}$ based on $\mathrm{E}_{2} \mathrm{C}_{16}$ content in the blends, $\Delta \mathrm{H}_{\mathrm{m}}$ based on $\mathrm{E}_{2} \mathrm{C}_{16}$ content in the graft copolymers had a higher value. The movement of grafted $\mathrm{E}_{2} \mathrm{C}_{16}$ chains is confined so that they cannot freely arrange to crystallize, causing the imperfection of the $\mathrm{E}_{2} \mathrm{C}_{16}$ crystals to increase and resulting in a decrease in enthalpy. This also demonstrates that the products were cellulose-based copolymers. 


\section{4. $P O M$}

Figure 5 shows POM photos of CA-g- $\mathrm{E}_{2} \mathrm{C}_{16}$ (A3), CP-g- $\mathrm{E}_{2} \mathrm{C}_{16}$ (P3), and CB-g- $\mathrm{E}_{2} \mathrm{C}_{16}$ (B3) copolymers heated in the temperature range of $20 \sim 80{ }^{\circ} \mathrm{C}$. As listed in Table 3 , the melting onset temperatures of $\mathrm{A} 3, \mathrm{P} 3$, and $\mathrm{B} 3$ are $8.0^{\circ} \mathrm{C}, 13.7^{\circ} \mathrm{C}$, and $14.2^{\circ} \mathrm{C}$, respectively. For $\mathrm{CA}-g-\mathrm{E}_{2} \mathrm{C}_{16}$ (A3), when the environmental temperature rose from $20^{\circ} \mathrm{C}$ to $50{ }^{\circ} \mathrm{C}$, the $\mathrm{E}_{2} \mathrm{C}_{16}$ side chain of the copolymer experienced melting, and its phase changed from crystalline to amorphous morphology. However, its macroscopic state did not change from the solid state. When the temperature continued to rise to 80 ${ }^{\circ} \mathrm{C}$, the macroscopic state of the copolymer still was not changed. This is because the melted $\mathrm{E}_{2} \mathrm{C}_{16}$ side chain is confined by the cellulosic backbone, and it cannot flow freely; therefore, the CA-g- $\mathrm{E}_{2} \mathrm{C}_{16}$ copolymer stayed in a solid state, on the whole. CP-g- $\mathrm{E}_{2} \mathrm{C}_{16}$ (P3) and CB-g- $\mathrm{E}_{2} \mathrm{C}_{16}$ (B3) copolymers also showed the same phenomenon. This demonstrated that the phase change type of the synthesized copolymers is solid-solid phase change; that is to say, CA-g- $\mathrm{E}_{2} \mathrm{C}_{16}, \mathrm{CP}-\mathrm{g}-\mathrm{E}_{2} \mathrm{C}_{16}$, and CB-g- $\mathrm{E}_{2} \mathrm{C}_{16}$ copolymers are a type of solid-solid phase material (SSPCM).

(a)

(b)
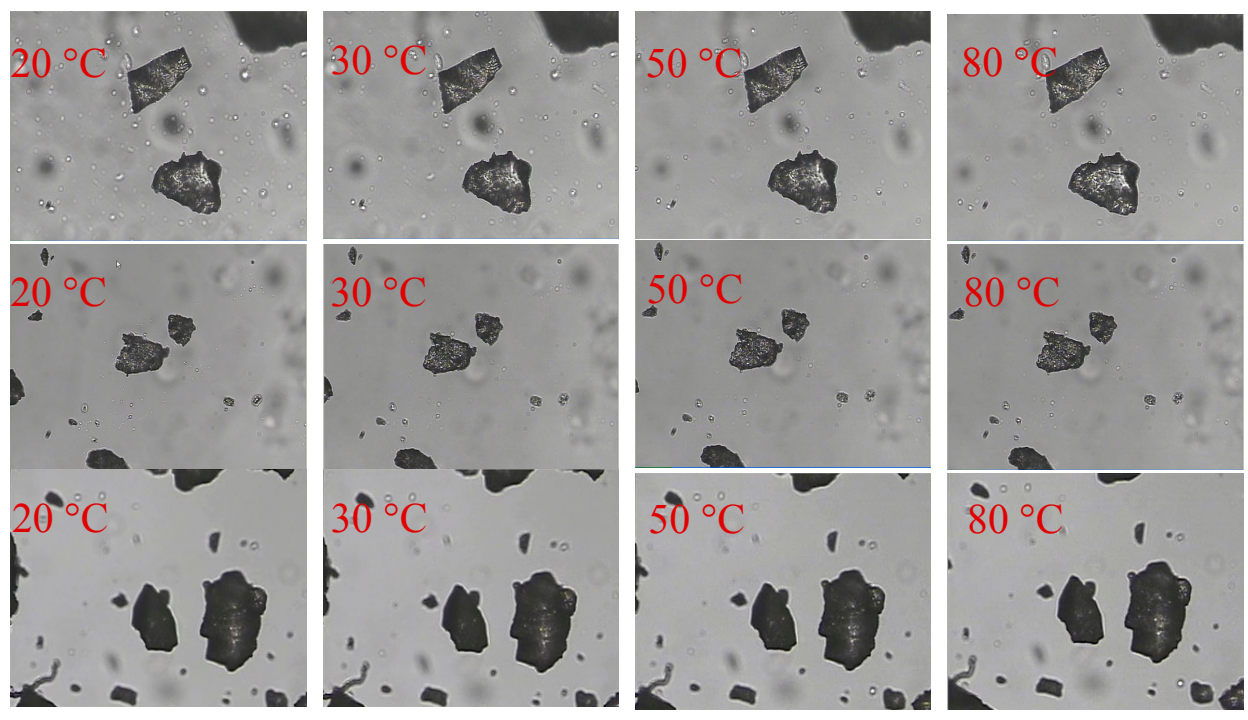

Figure 5. Polarized light microscopy (POM) photos of (a) CA-g- $\mathrm{E}_{2} \mathrm{C}_{16}$ (A3), (b) $\mathrm{CP}-\mathrm{g}-\mathrm{E}_{2} \mathrm{C}_{16}$ (P3), and (c) $\mathrm{CB}-\mathrm{g}-\mathrm{E}_{2} \mathrm{C}_{16}$ (B3) copolymers at different temperatures.

\subsection{TGA}

The thermal stability of cellulose, $\mathrm{E}_{2} \mathrm{C}_{16}, \mathrm{CA}-\mathrm{g}-\mathrm{E}_{2} \mathrm{C}_{16}, \mathrm{CP}-\mathrm{g}-\mathrm{E}_{2} \mathrm{C}_{16}$, and CB-g- $\mathrm{E}_{2} \mathrm{C}_{16}$ copolymers were investigated by TG. It can be observed from Figure 6 and Table 4 that all the copolymers are not degradable and that almost no mass loss occurs before $280^{\circ} \mathrm{C}$. The onset decomposition of cellulose occurs at $319^{\circ} \mathrm{C}[16]$. The thermal stability of $\mathrm{CA}-\mathrm{g}-\mathrm{E}_{2} \mathrm{C}_{16}, \mathrm{CP}-\mathrm{g}-\mathrm{E}_{2} \mathrm{C}_{16}$, and $\mathrm{CB}-\mathrm{g}-\mathrm{E}_{2} \mathrm{C}_{16}$ copolymers dropped to $294^{\circ} \mathrm{C}, 288^{\circ} \mathrm{C}$, and $289^{\circ} \mathrm{C}$, respectively. The lower thermal stability mainly is a result of the introduction of the fatty acid anhydride and $\mathrm{E}_{2} \mathrm{C}_{16}$, which significantly decrease the crystallinity of cellulose [17]. Furthermore, the presence of grafted side chains on the cellulose backbone was confirmed. It is worthy to note that the $\mathrm{T}_{\mathrm{do}}$ of $\mathrm{CA}-\mathrm{g}-\mathrm{E}_{2} \mathrm{C}_{16}, \mathrm{CP}-\mathrm{g}-\mathrm{E}_{2} \mathrm{C}_{16}$, and CB-g- $\mathrm{E}_{2} \mathrm{C}_{16}$ copolymers were still much higher than that of the raw $\mathrm{E}_{2} \mathrm{C}_{16}$ due to the confinement derived from the cellulose backbone, and were almost independent of the DS value. Compared with pure $\mathrm{E}_{2} \mathrm{C}_{16}$, the thermal stabilities of the cellulose-g- $\mathrm{E}_{2} \mathrm{C}_{16}$ copolymers were improved by approximately $42 \sim 50{ }^{\circ} \mathrm{C}$. It is also shown that the thermal stability was improved gradually with the increase of DS. It was concluded that CA-g- $\mathrm{E}_{2} \mathrm{C}_{16}, \mathrm{CP}-\mathrm{g}-\mathrm{E}_{2} \mathrm{C}_{16}$, and $\mathrm{CB}-\mathrm{g}-\mathrm{E}_{2} \mathrm{C}_{16}$ copolymers can be applied as a type of SSPCM and show thermal stability in a high-temperature environment. 

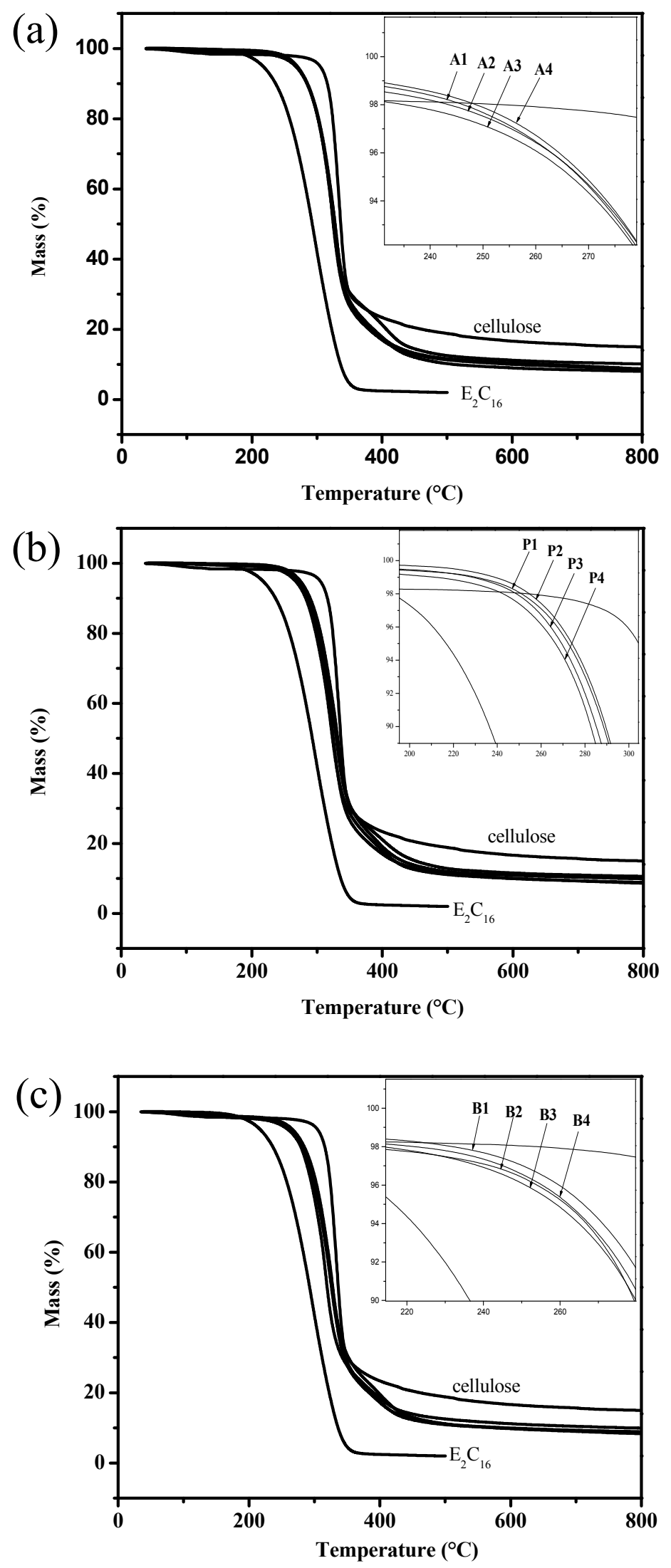

Figure 6. TG analysis of cellulose, $\mathrm{E}_{2} \mathrm{C}_{16}$, (a) $\mathrm{CA}-\mathrm{g}-\mathrm{E}_{2} \mathrm{C}_{16}$, (b) $\mathrm{CP}-\mathrm{g}-\mathrm{E}_{2} \mathrm{C}_{16}$, and (c) CB-g- $\mathrm{E}_{2} \mathrm{C}_{16}$ copolymers. 
Table 4. Thermal stabilities of cellulose, $\mathrm{E}_{2} \mathrm{C}_{16}, \mathrm{CA}-\mathrm{g}-\mathrm{E}_{2} \mathrm{C}_{16}, \mathrm{CP}-\mathrm{g}-\mathrm{E}_{2} \mathrm{C}_{16}$, and CB-g- $\mathrm{E}_{2} \mathrm{C}_{16}$ copolymers.

\begin{tabular}{cccccc}
\hline Sample No. & $\boldsymbol{D S}_{\mathbf{1}}$ & $\boldsymbol{D S}_{\mathbf{2}}$ & $\mathbf{T}_{\mathbf{d o}}\left({ }^{\circ} \mathbf{C}\right)$ & $\mathbf{T}_{\mathbf{d p}}\left({ }^{\circ} \mathbf{C}\right)$ & Mass Loss (\%) \\
\hline Cellulose & - & - & 319 & 335 & 85.4 \\
$\mathrm{E}_{2} \mathrm{C}_{16}$ & - & - & 246 & 295 & 98.0 \\
$\mathrm{~A} 1$ & 0.35 & 0.59 & 294 & 331 & 92.0 \\
$\mathrm{~A} 2$ & 0.58 & 0.75 & 295 & 328 & 89.9 \\
$\mathrm{~A} 3$ & 0.75 & 0.86 & 295 & 324 & 91.3 \\
$\mathrm{~A} 4$ & 1.09 & 0.52 & 296 & 325 & 90.8 \\
P1 & 0.36 & 0.62 & 296 & 333 & 90.1 \\
P2 & 0.55 & 0.80 & 295 & 330 & 89.4 \\
P3 & 0.79 & 0.97 & 294 & 325 & 91.4 \\
P4 & 1.00 & 0.88 & 288 & 321 & 91.2 \\
B1 & 0.35 & 0.79 & 296 & 329 & 91.2 \\
B2 & 0.54 & 0.93 & 289 & 317 & 90.1 \\
B3 & 0.75 & 1.02 & 293 & 328 & 91.7 \\
B4 & 1.04 & 0.91 & 290 & 326 & 91.1 \\
\hline
\end{tabular}

\subsection{WAXD}

Figure 7 shows the WAXD patterns of cellulose, $\mathrm{E}_{2} \mathrm{C}_{16}, \mathrm{CA}-\mathrm{g}-\mathrm{E}_{2} \mathrm{C}_{16}, \mathrm{CP}-\mathrm{g}-\mathrm{E}_{2} \mathrm{C}_{16}$, and CB-g- $\mathrm{E}_{2} \mathrm{C}_{16}$ copolymers that were obtained to investigate the change in the crystal type of $\mathrm{E}_{2} \mathrm{C}_{16}$ before and after grafting. There are three diffraction peaks in the WAXD pattern of cellulose, whose locations are $14.8^{\circ}$, $16.4^{\circ}$, and $22.6^{\circ}$, and the d-spacings are $0.60 \mathrm{~nm}, 0.54 \mathrm{~nm}$, and $0.39 \mathrm{~nm}$, respectively. $\mathrm{E}_{2} \mathrm{C}_{16}$ shows two sharp peaks centered at $21.2^{\circ}$ and a small peak centered at $23.7^{\circ}$, with d-spacings of $0.42 \mathrm{~nm}$ and $0.38 \mathrm{~nm}$, and the crystal type of $\mathrm{E}_{2} \mathrm{C}_{16}$ is hexagonal [18]. It is reported that the characteristic diffraction peaks (110) and (020) of cellulose II are locate at $19.9^{\circ}$ and $22.1^{\circ}$ [19]. It can be seen that CA-g- $\mathrm{E}_{2} \mathrm{C}_{16}$ copolymers show diffraction peaks centered at $20.7^{\circ}(\mathrm{d}$-spacing $=0.43 \mathrm{~nm})$ and $21.6^{\circ}$ $(\mathrm{d}$-spacing $=0.41 \mathrm{~nm})$, which were close to the characteristic diffraction peaks of cellulose II $\left(2 \theta=19.9^{\circ}\right)$ and $\mathrm{E}_{2} \mathrm{C}_{16}\left(2 \theta=21.2^{\circ}\right)$, respectively. However, the intensity of the three types of cellulose-based copolymers were all weaker than that of $\mathrm{E}_{2} \mathrm{C}_{16}$ and cellulose itself, as expected. It is demonstrated that the transformation from cellulose I to cellulose II also occurred after the dissolution and regeneration in $\mathrm{AmimCl}$. The analysis above indicated that the crystalline form of the grafted $\mathrm{E}_{2} \mathrm{C}_{16}$ side chain onto the cellulose backbone is not affected by the cellulose molecule. Moreover, $\mathrm{CP}-\mathrm{g}-\mathrm{E}_{2} \mathrm{C}_{16}$ (P3) and $\mathrm{CB}-\mathrm{g}-\mathrm{E}_{2} \mathrm{C}_{16}$ (B3) copolymers also showed the same phenomenon. Figure 8 shows contradistinctive WAXD patterns of $C A-g-E_{2} C_{16}, C P-g-E_{2} C_{16}$, and CB-g- $E_{2} C_{16}$ copolymers. It can be seen that the diffraction peak locations of these three copolymers are consistent, which indicated that a formed short side chain had no effect on the crystal type of $\mathrm{E}_{2} \mathrm{C}_{16}$.

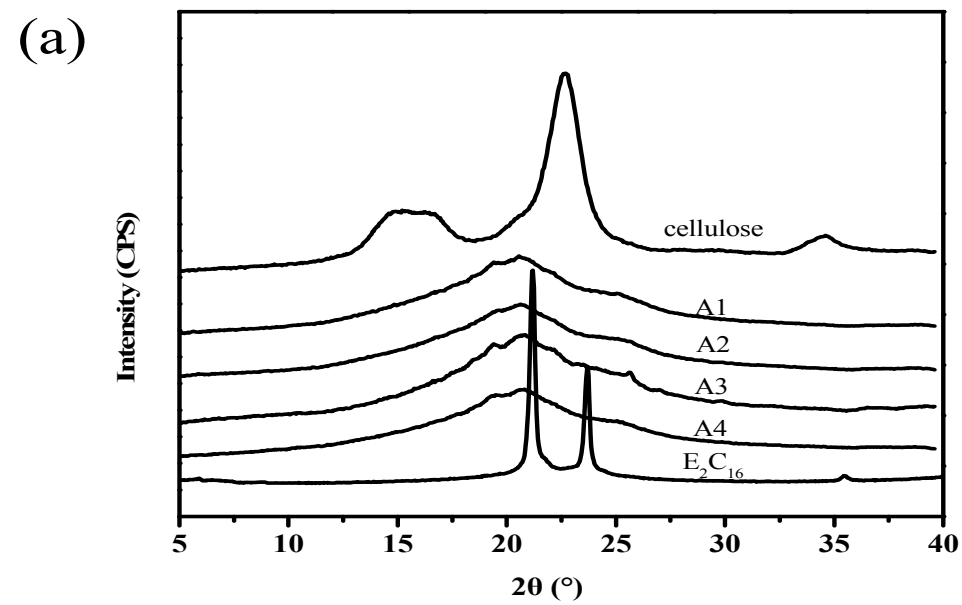

Figure 7. Cont. 
(b)

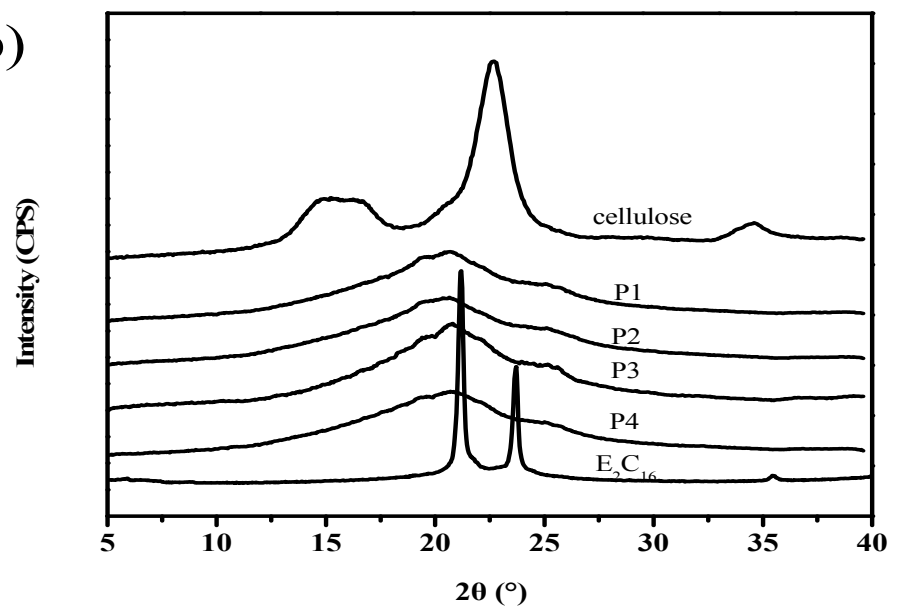

(c)

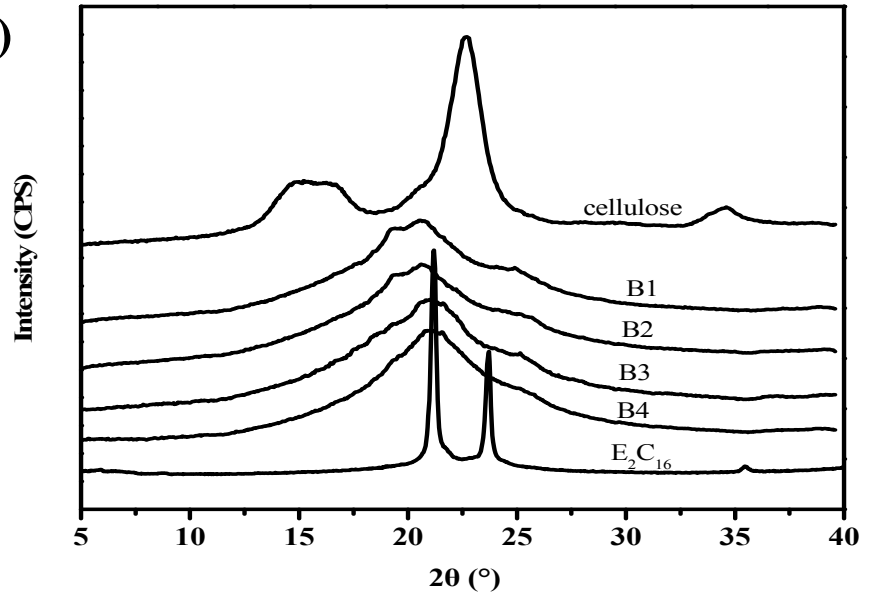

Figure 7. WAXD patterns of cellulose, $\mathrm{E}_{2} \mathrm{C}_{16}$, (a) $\mathrm{CA}-\mathrm{g}-\mathrm{E}_{2} \mathrm{C}_{16}$, (b) $\mathrm{CP}-\mathrm{g}-\mathrm{E}_{2} \mathrm{C}_{16}$, and (c) CB-g- $\mathrm{E}_{2} \mathrm{C}_{16}$ copolymers.

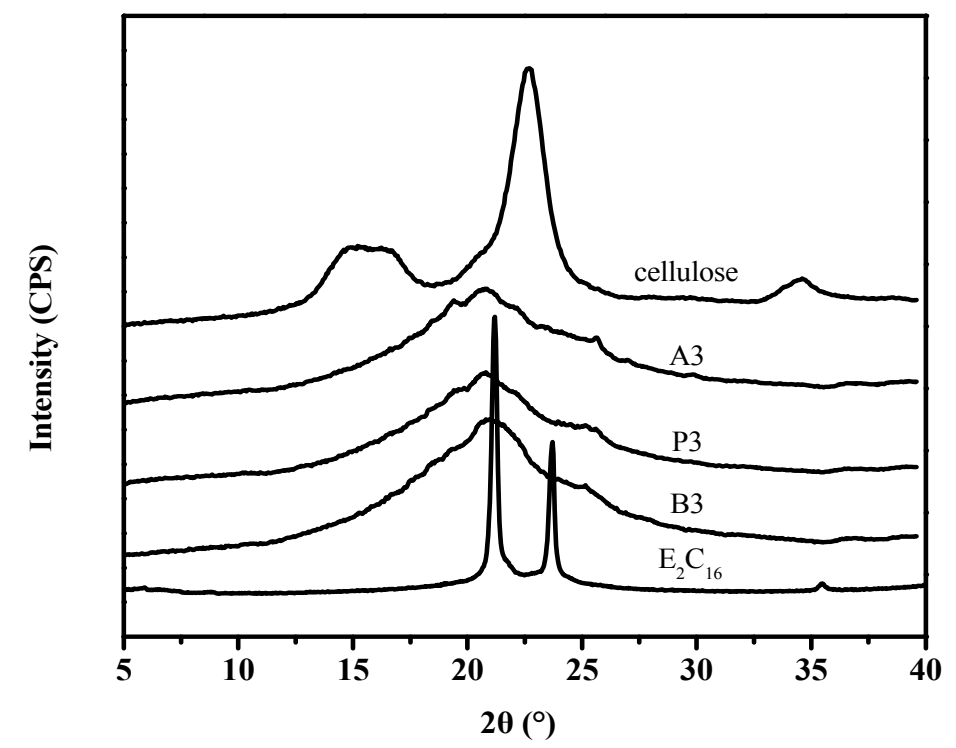

Figure 8. WAXD patterns of cellulose, $\mathrm{E}_{2} \mathrm{C}_{16}, \mathrm{CA}-\mathrm{g}-\mathrm{E}_{2} \mathrm{C}_{16}(\mathrm{~A} 3), \mathrm{CP}-\mathrm{g}-\mathrm{E}_{2} \mathrm{C}_{16}$ (P3), and CB-g- $\mathrm{E}_{2} \mathrm{C}_{16}$ (B3) copolymers. 


\section{Conclusions}

Cellulose was esterified using short-chain fatty acid anhydrides (acetic anhydride, propionic anhydride, and butyric anhydride), followed by grafting of polyoxyethylene (2) hexadecyl ether $\left(\mathrm{E}_{2} \mathrm{C}_{16}\right)$ using toluene-2,4-diisocyanate as a coupling agent and with the feeding molar ratio of $\mathrm{E}_{2} \mathrm{C}_{16} / \mathrm{AGU}$ fixed at 4:1, and then a series of CA-g- $\mathrm{E}_{2} \mathrm{C}_{16}, \mathrm{CP}-\mathrm{g}-\mathrm{E}_{2} \mathrm{C}_{16}$, and CB-g- $\mathrm{E}_{2} \mathrm{C}_{16}$ copolymers were successfully obtained. It is shown that with the anhydride/AGU ratio increasing, the DS value of $\mathrm{E}_{2} \mathrm{C}_{16}$ was first increased and then decreased. With the carbon chain length increasing, the DS value of $\mathrm{E}_{2} \mathrm{C}_{16}$ showed a trend of increasing continuously. The phase transition temperature and enthalpy of the copolymers increased with increasing DS value of $\mathrm{E}_{2} \mathrm{C}_{16}$. When the ratio of butyric anhydride/AGU was 1.5:1, the $\mathrm{DS}$ of $\mathrm{E}_{2} \mathrm{C}_{16}$ was up to the maximum value of 1.02, and the corresponding melting enthalpy and crystallization enthalpy were $32 \mathrm{~J} / \mathrm{g}$ and $30 \mathrm{~J} / \mathrm{g}$, respectively. All copolymers showed solid-solid phase change behaviors. The heat resistant temperature of cellulose-based solid-solid phase change materials is always higher than $270{ }^{\circ} \mathrm{C}$. After the grafting reaction, the crystallinity of $\mathrm{E}_{2} \mathrm{C}_{16}$ is decreased, but the crystal type is still hexagonal.

Author Contributions: For research articles with several authors, a short paragraph specifying their individual contributions must be provided. The following statements should be used "Na Han and Xingxiang Zhang conceived and designed the experiments; Wanyong Yu and Na Han performed the experiments; Na Han and Yongqiang Qian analyzed the data; Na Han, Xingxiang Zhang and Wei Li contributed reagents/materials/analysis tools; Wanyong Yu and Na Han wrote the paper". Authorship must be limited to those who have contributed substantially to the work reported.

Acknowledgments: This work was supported by the National Natural Science Fund of China (No. 51573135; No. 21206123); Postdoctoral Program projects (No. 2014M551026, No. 201402011); Tianjin Municipal Science and Technology Project (No. 16YFZCSF00120, No. 16JCYBJC17100) for financial support.

Conflicts of Interest: The authors declare no conflict of interest.

\section{References}

1. Isik, M.; Sardon, H.; Mecerreyes, D. Ionic Liquids and Cellulose: Dissolution, Chemical Modification and Preparation of New Cellulosic Materials. Int. J. Mol. Sci. 2014, 15, 11922-11940. [CrossRef] [PubMed]

2. Zhang, Y.; Li, H.F.; Li, X.D.; Gibril, M.E.; Han, K.Q. Green chemical preparation of cellulose/high performance elastomer blend fibers by melt-spinning method. J. Polym. Res. 2013, 20, 171. [CrossRef]

3. Zhang, Y.; Li, H.F.; Li, X.D.; Gibril, M.E.; Yu, M.H. Chemical modification of cellulose by in situ reactive extrusion in ionic liquid. Carbohyd. Polym. 2014, 99, 126-131. [CrossRef] [PubMed]

4. Barthel, S.; Heinze, T. Acylation and carbanilation of cellulose in ionic liquids. Green Chem. 2006, 8, 301-306. [CrossRef]

5. Gyorgy, S.; Attila, D.; Szilvia, K. Molecular structure and properties of cellulose acetate chemically modified with caprolactone. Eur. Polym. J. 2008, 44, 357-365.

6. Labafzadeh, S.R.; Vyavaharkar, K.; Kavakka, J.S. Amination thiolation of chloroacetyl cellulose through reactive dissolution in $\mathrm{N}, \mathrm{N}$-dimethylformamide. Carbohyd. Polym. 2015, 116, 60-66. [CrossRef] [PubMed]

7. Saleh, H.; Yvonne, A.; Mikael, S. All-cellulose nanocomposite fibers produced by melt spinning cellulose acetate butyrate and cellulose nanocrystals. Cellulose 2014, 21, 2665-2678.

8. Teramoto, Y.; Nishio, Y. Cellulose diacetate-graft-poly(lactic acid)s: Synthesis of wide-ranging compositions and their thermal and mechanical properties. Polymer 2003, 44, 2071-2079. [CrossRef]

9. Yan, C.; Zhang, J.M.; Lv, Y.X. Thermoplastic Cellulose-graft-poly(L-lactide) copolymers homogeneously synthesized in an lonic liquid with 4-dimethylamininopyridine catalyst. Biomacromolecules 2009, 10, 2013-2018. [CrossRef] [PubMed]

10. Qian, Y.Q.; Han, N.; Bo, Y.W.; Tan, L.L.; Zhang, L.F.; Zhang, X.X. Homogeneous synthesis of cellulose acrylate-g-poly ( $n$-alkyl acrylate) solid-solid phase change materials via free radical polymerization. Carbohydr. Polym. 2018, 193, 129-136. [CrossRef]

11. Vaca-Garcia, C.; Gozzelino, G.; Glasser, W.G.; Borredon, M.E. Dynamic mechanical thermal analysis transitions of partially and fully substituted cellulose fatty esters. J. Polym. Sci. Polym. Phys. 2003, 41, 281-288. [CrossRef] 
12. Xiao, P.; Zhang, J.M.; Feng, Y.; Wu, J.; He, J.S.; Zhang, J. Synthesis, characterization and properties of novel cellulose derivatives containing phosphorus: Cellulose diphenyl phosphate and its mixed esters. Cellulose 2014, 21, 2369-2378. [CrossRef]

13. Luan, Y.H.; Wu, J.; Zhan, M.S.; Zhang, J.M.; Zhang, J.; He, J.S. “One pot" homogeneous synthesis of thermoplastic cellulose acetate-graft-poly(L-lactide) copolymers from unmodified cellulose. Cellulose 2013, 20, 327-337. [CrossRef]

14. Li, Y.; Wu, M.; Liu, R.G.; Huang, Y. Cellulose-based solid-solid phase change materials synthesized in ionic liquid. Sol. Energy Mater. Sol. Cells 2009, 93, 1321-1328. [CrossRef]

15. Luan, Y.H.; Zhang, J.M.; Zhan, M.S.; Wu, J.; Zhang, J.; He, J.S. Highly efficient propionylation and butyralation of cellulose in an ionic liquid catalyzed by 4-dimethylminopyridine. Carbohyd. Polym. 2013, 92, 307-311. [CrossRef] [PubMed]

16. Han, N.; Li, Z.N.; Zhang, X.X.; Yu, W.Y.; Chen, X.Y.; Wang, D.; Li, J.B. Synthesis and Characterization of Cellulose-g-Polyoxyethylene (2) Hexadecyl Ether Solid-Solid Phase Change Materials. Cellulose 2016, 23, 1663-1674. [CrossRef]

17. Mohamed, J.; Nasko, T.; Ivo, H. Biobased and sustainable alternative route to long-chain cellulose esters. Biomacromolecules 2017, 18, 498-504.

18. Zhang, Z.L.; Zhang, X.X.; Shi, H.F.; Li, W.; Meng, J.Y. Poly(diethylene glycol hexadecyl ether acrylate)(PC16E2AA) and poly(acrylonitrile-co-vinylidene chloride)/PC16E2AA sheath/core thermo-regulated sub-microfibers. Text. Res. J. 2016, 86, 493-501. [CrossRef]

19. Zhang, H.; Wu, J.; Zhang, J.; He, J.S. 1-Allyl-3-methylimidazolium Chloride Room Temperature Ionic Liquid: A New and Powerful Nonderivatizing Solvent for Cellulose. Macromolecules 2005, 38, 8272-8277. [CrossRef]

(C) 2018 by the authors. Licensee MDPI, Basel, Switzerland. This article is an open access article distributed under the terms and conditions of the Creative Commons Attribution (CC BY) license (http:/ / creativecommons.org/licenses/by/4.0/). 